\title{
Effect of Peer Mentoring on Quality of Life among CKD Patients: Randomized Controlled Trial
}

\author{
Nasrollah Ghahramani Vernon M. Chinchilli Jennifer L. Kraschnewski \\ Eugene J. Lengerich Christopher N. Sciamanna \\ Pennsylvania State University, College of Medicine, Hershey, PA, USA
}

\section{Keywords}

Chronic kidney disease $\cdot$ Quality of life $\cdot$ Peer mentoring

\begin{abstract}
Introduction: $\mathrm{CKD}$ is associated with decreased quality of life $(\mathrm{QOL})$. Peer mentoring (PM) leads to improved $\mathrm{QOL}$ in various chronic diseases. The effectiveness of PM on QOL of patients with CKD has not been previously studied. We conducted a randomized clinical trial to test the effectiveness of face-to-face (FTF) and online mentoring by trained peers, compared with usual care, on CKD patients' QOL. Methods: We randomized 155 patients in one of 3 groups: (1) FTF PM $(n=52)$, (2) online PM $(n=52)$, and (3) textbook only $(n=51)$. Peer mentors were patients with CKD, who received formal training through $16 \mathrm{~h}$ of instruction. Participants in all 3 groups received a copy of an informational textbook about CKD. Participants assigned to PM received either 6 months of FTF or online PM. The outcomes included time-related changes in domain scores of the Kidney Disease Quality of Life (KDQOL)-36 for each of the groups over the 18-month study period. Results: Compared with baseline, online PM led to improved scores in domains of the KDQOL-36 at 18 months: Effects of Kidney Disease $(p=0.01)$, Burden of Kid-
\end{abstract}

ney Disease $(p=0.01)$, Symptoms and Problems of Kidney Disease ( $p=0.006)$, SF-12 Physical Composite Summary ( $p=$ $0.001)$, and SF-12 Mental Composite Summary $(p<0.001)$. There were no statistically significant changes from baseline in domain scores of KDQOL-36 within the FTF PM and textbook-only groups. Conclusions: Among patients with CKD, online PM led to increased scores in domains of the KDQOL36 at 18 months. The study was limited to English-speaking subjects with computer literacy and internet access.

(c) 2021 The Author(s) Published by S. Karger AG, Basel

\section{Introduction}

CKD and the resulting ESRD are significant global health problems. In 2016, the incidence of ESRD in the USA was 124,675 , and the prevalence reached 726,331 , among the highest rates in the world [1]. In addition to substantial mortality, morbidity, and cost, CKD has significant negative effects on quality of life (QOL) $[2,3]$. Decreased QOL is correlated with mortality among CKD pa-

Trial registration: Clinicaltrials.gov identifier: NCT02429115. karger@karger.com www.karger.com/kdd

Karger ${ }^{\prime \prime}$

BOPEN ACCESS
C) 2021 The Author(s)

Published by S. Karger AG, Basel

This is an Open Access article licensed under the Creative Commons Attribution-NonCommercial-4.0 International License (CC BY-NC) (http://www.karger.com/Services/OpenAccessLicense), applicable to the online version of the article only. Usage and distribution for commercial purposes requires written permission.
Nasrollah Ghahramani

Pennsylvania State University, College of Medicine

500 University Drive, PO Box

Hershey, PA 17033-0850 (USA)

nghahramani@pennstatehealth.psu.edu 
tients [4]. Disease-specific information and knowledge is associated with improved QOL. Providing CKD patients with information results in patient-centered care, alleviates anxiety, enables the individual to cope, facilitates awareness, and improves self-management adherence [5, 6]. Educating patients with $\mathrm{CKD}$ is associated with improved outcomes, including QOL, and has been recommended as an area of priority in systematic reviews, professional guidelines, and consensus conferences involving professional societies, providers, patients, and stakeholders [7-11]. In response to these recommendations, education programs have been developed. Despite these educational programs, however, studies have highlighted suboptimal understanding of CKD and its treatment options by patients $[12,13]$, and significant gaps have been identified in desired and provided information [14].

Findings from systematic reviews indicate that CKD patients place value on relationships and being part of social networks of family, friends, staff, and other patients. These networks provide strength and support [15]. Peers with experience in managing their CKD may be in a unique position to communicate knowledge and confidence to a recently diagnosed patient in a more personalized manner. Patients with CKD are interested in the experiences of others, not as a source of medical information [16] but to discuss ideas on how to cope with their disease [17]. Comparing themselves with their peers reassures them of their own situation and reduces sense of isolation $[18,19]$. Heisler [20] has proposed several models of peer support. These models include professional-led group visits, peer-led self-management training, peer coaches, community health workers, support groups, telephonebased peer support, and web- and email-based programs. The effectiveness of peer mentoring (PM) has been attributed to the nonhierarchical, reciprocal relationship that is created by sharing similar experiences [21]. Relationshipcentered mentoring by trained peers is an effective strategy that provides individualized, patient-centered information. PM has been shown to lead to improvements in activation of patients to participate in their own care, confidence in care, and multiple outcomes in various chronic diseases [22-29]. However, the optimal delivery of PM for patients with CKD is unknown, and information about the impact of trained mentors on the care of patients with CKD is lacking. More specifically, a peer-led CKD intervention has not been assessed for its impact on patient QOL. To address this issue, we examined the impact of face-to-face (FTF) and online PM on QOL among CKD patients. We hypothesized that a formal structured mentoring program will lead to improved QOL.

\section{Materials and Methods}

\section{Study Overview}

We conducted a randomized clinical trial to test the effectiveness of mentoring by trained peers on CKD patients' QOL as measured by Kidney Disease Quality of Life-36 (KDQOL-36). We randomized CKD patients into 3 groups: (1) FTF PM plus textbook about CKD, (2) online PM plus textbook about CKD, and (3) only textbook about CKD. The research was conducted according to principles having their origin in the Declaration of Helsinki. Written informed consent was obtained from all participants. The protocol was reviewed and approved by the Pennsylvania State University College of Medicine Institutional Review Board. The clinical trial was registered with Clinicaltrials.gov (NCT02429115).

\section{Study Setting}

We conducted the trial among patients residing in one of the 28 counties served by the Kidney Foundation of Central Pennsylvania (KFCP). The wide recruitment area included urban and rural areas, as well as various racial, ethnic, and socioeconomic categories.

Mentor Training (The Patient and Family Partner Program)

Since 2004, the KFCP has operated a comprehensive patient engagement and empowerment program (Patient and Family Partner Program [PFPP]). The PFPP was envisioned by a kidney transplant recipient, who was a registered nurse and a member of the KFCP Board of Directors [30]. She partnered with a renal social worker and a transplant coordinator to develop a PM program for patients with ESRD. Following a thorough literature and internet search, the founding group developed a preliminary curriculum for training of the peer mentors. Mentors were patients with CKD stage 4 or 5,18 years or older, who received formal training through $16 \mathrm{~h}$ of instruction facilitated by patients, caregivers, and health care professionals. The curriculum for the training of mentors is shown in online suppl. material (for all online suppl. material, see www.karger.com/doi/10.1159/000514477) (Appendix A). Upon successful completion of the training, each peer mentor received a certificate as a certified mentor. Recognizing the importance of continuing education following the initial training, refresher courses were conducted on a quarterly basis. These sessions featured discussions among mentors about their actual experiences and a focused review of communication skills. Each mentor was required to attend at least one refresher course per year to maintain certification. Through the PFPP, trained CKD patients and their caregivers served as volunteer peer mentors to other CKD patients and their caregivers to help them successfully engage in their own care [31].

\section{Participants}

We recruited participants from patients with CKD stage 4 or 5 from nephrology practices and dialysis units in central Pennsylvania. Inclusion criteria were (1) patients diagnosed with stage 4 or 5 CKD by a physician, (2) at least 18 years of age, (3) able to read and write in English at the $8^{\text {th }}$ grade level, (4) have access to a computer with internet and email capability, and (5) willing to participate. Exclusion criteria were (1) participation in previous PM for CKD, (2) inability to provide consent, (3) currently a prisoner, and (4) physical condition preventing active participation in the mentoring program as determined by a primary nephrologist. We sent information packets about the study to dialysis units and nephrology practices asking renal professionals, most of whom are familiar 
with PFPP, to distribute them among patients. The flyers encouraged patients who might be interested in exploring being matched with a mentor to contact either their social worker or the program coordinator. Following informed consent, candidates underwent permuted block randomization with 1:1:1 allocation into "FTF PM," "online PM," and "textbook-only." The investigators did not have access to the identity of the participant assignment until they confirmed that the participant was eligible for enrollment. Recruitment occurred continuously until we achieved the target sample sizes. In the initial screening questionnaire, we asked the potential candidates who declined to participate to indicate reasons for declining. To improve retention, we compensated participants with 50 USD for completion of the baseline assessment and each followup assessment for a total of 150 USD per participant.

Interventions and Comparators

The 3 interventions were (1) FTF PM group, in which patients received 6 months of FTF PM; (2) online PM group, in which patients received 6 months of PM through an interactive online platform; and (3) textbook-only group. We used the PFPP as the mentoring program for the intervention groups. Participants in all 3 groups received a copy of the PFPP textbook, which contained detailed information about kidney disease, and that was written at an 8 th grade reading level. The choice of interventions emerged following a review of mentor and mentee evaluations and a focus group discussion involving dialysis and transplant patients, renal social workers, director of the KFCP, PFPP program coordinator, and the PFPP medical director (N.G.). We developed the online intervention based on the focus group discussions and evidenced that web-based peer support is a potential alternative to FTF mentoring, particularly for populations with limited ability to travel and for regions with limited resources. Twenty six of the previously trained peer mentors participated. Each mentor served as a peer to 4 mentees ( $2 \mathrm{FTF}$ and 2 online).

\section{FTF PM Group}

Following initial introductions, the mentors initiated the discussion by presenting an overview of the program. The mentors and the mentees also reviewed mutual goals and expectations at the time of initial meeting. Mentors encouraged mentees to familiarize themselves with the textbook and to ask questions or share any concerns. The mentors responded to questions during phone calls or at monthly meetings. The required minimum frequency of contact by mentors was weekly by telephone, monthly in an FTF visit, and more frequently as initiated by the mentees. At the end of each month, the mentor presented the log of the meetings to the program coordinator.

\section{Online PM Group}

Mentor and mentees communicated using a secure, passwordprotected, interactive online platform. The platform consisted of a web-based bulletin-board designed specifically for this study. We developed the contents of the online mentoring program according to the themes that emerged from qualitative interviews and discussions with experienced peer mentors, patients, caregivers, and health care professionals. All communications between mentors and mentees were online. Following initial introductions, the mentors initiated the discussion by presenting an overview of the program. The mentors and the mentees also reviewed mutual goals and expectations at the time of initial communication. Mentors encour-

Effect of Peer Mentoring on Quality of Life among CKD Patients aged mentees to familiarize themselves with the textbook and to post any questions or updates to their status using verbal statements or mood and symptom icons. The mentors responded to questions or posted a query about the updated status. The mentors sent a weekly reminder email to the mentees to log on to the website to review posted contents and to post a weekly action plan, as well as any problems they wish to discuss with their individual mentors. The required minimum frequency of contact by mentors was weekly and more frequently as initiated by the mentees. The program coordinator maintained regular contact with the mentors and mentees and closely monitored the frequency and content of the interactions to ensure appropriate communication, to correct inaccurate information posted by participants, and to direct the mentees to their care providers in situations requiring medical intervention.

Textbook-Only Group

This group received the textbook with instructions to ask care providers questions. The textbook contains information about the structure and function of the kidneys, causes of kidney failure, dietary considerations in kidney disease, and modes of treatment for CKD. Adherence to review of material was by self-report.

\section{Outcomes}

The primary outcome was improvement in health-related QOL (HRQOL) as measured by the KDQOL-36 instrument from the Rand Corporation. At baseline and 12 and 18 months, the patients completed the KDQOL-36 instrument. This 36-item instrument was developed as a self-reported, HRQOL tool designed specifically for patients with CKD [32]. The KDQOL-36 combines the 12-item Short-Form Health Survey (SF-12) and 24 kidney disease-specific targeted domains. The SF-12 yields the Physical Composite Summary (PCS) and the Mental Composite Summary (MCS). The kidney disease-specific targeted domains comprise 3 scales: the 4-item Burden of Kidney Disease (BKD), the 12-item Symptoms and Problems of Kidney Disease (SPKD), and the 8 -item Effects of Kidney Disease (EKD). The scales are scored on a $0-100$ scale, with higher numbers indicating better HRQOL [33]. The KDQOL-36 has been validated among patients with CKD with predictive validity for several outcomes including survival; it is the most widely used measure of HRQOL in the nephrology literature [33-39]. A single KDQOL-36 Summary Score (KSS) has recently been proposed by Peipert et al. [40]. In this report, we present the results in the form of separate subscale summaries of the KDQOL-36. Additional outcomes of the study were patient activation and caregiver burden which will be reported separately.

\section{Sample Size Calculations and Power}

A 10-point change in the domains of KDQOL-36 has been associated with significant changes in clinically relevant outcomes [41]. Considering a minimally clinically important difference of 10 , mean of 63, an SD of 13 [41], alpha of 0.05 , and comparison of 3 means, we determined that a sample size of 39 per group would yield a statistical power of 0.8 . Assuming a dropout rate of $15 \%$ [42], the total target sample size was 132 patients (44 for each of the 3 study groups).

\section{Time Frame for the Trial}

According to individual studies $[43,44]$, a systematic review of 15 studies [45], a qualitative synthesis of 25 studies [46], and a re- 


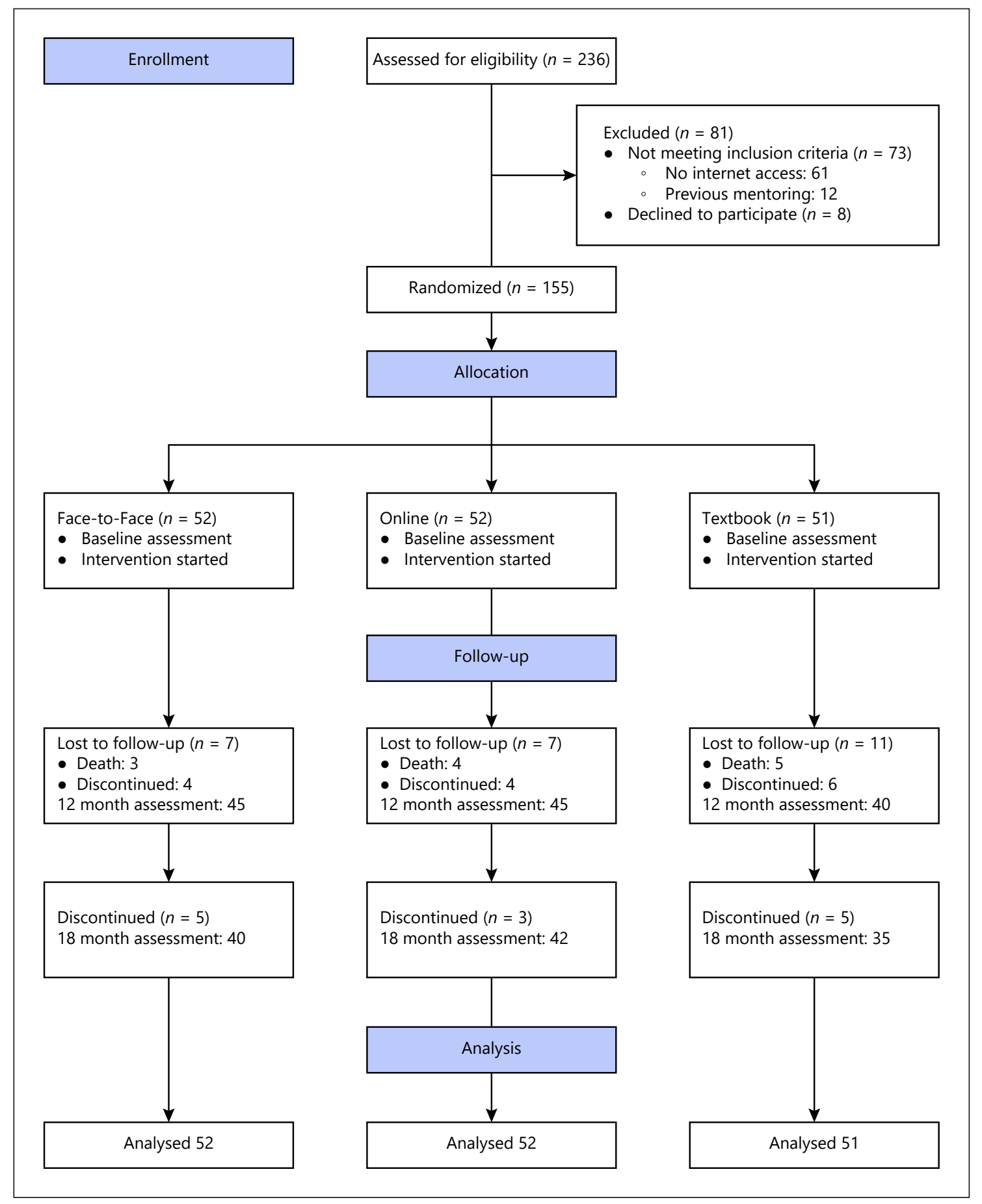

Fig. 1. CONSORT diagram for flow of patients through the trial.

view of 11 studies [47], the effective duration of PM for chronic diseases has ranged from 6 weeks to 2 years. Based on these reports, we selected 6 months as the length of intervention. Sustainability of any QOL effect has ranged from 3 months [48] to 18 months [49]. We chose 12-month postenrollment (6 months after completion of intervention) for quantitative follow-up assessments. To evaluate any sustained intervention effect, we repeated assessments at 18 months.

Data Collection and Sources

Quantitative data for this clinical trial included responses to self-administered survey instruments delivered by US mail. We 
Table 1. Baseline characteristics of patients by the intervention group

\begin{tabular}{|c|c|c|c|c|c|}
\hline Patients in each group, $n$ & 52 & 52 & 51 & 155 & - \\
\hline White, $n(\%)$ & $24(46)$ & $26(50)$ & $24(47)$ & $74(47.7)$ & 0.9 \\
\hline Hispanic, $n(\%)$ & $5(10)$ & $5(10)$ & $7(14)$ & $17(11.0)$ & 0.74 \\
\hline Age, years & & & & & 0.64 \\
\hline $54<$ age $\leq 62$ & $12(23)$ & $15(29)$ & $12(23.53)$ & $39(25.2)$ & 0.75 \\
\hline $62<$ age & $15(29)$ & $9(17)$ & $12(23.53)$ & $36(23.2)$ & 0.38 \\
\hline Married, $n(\%)$ & $16(31)$ & $21(40)$ & $21(41)$ & $58(37.4)$ & 0.48 \\
\hline Attended or completed college, $n(\%)$ & $22(42)$ & $30(58)$ & $25(49)$ & $77(49.7)$ & 0.29 \\
\hline Employed, $n(\%)$ & $13(25)$ & $17(33)$ & $16(31)$ & $46(29.7)$ & 0.66 \\
\hline Rural, $n(\%)$ & $4(8)$ & $7(14)$ & $9(18)$ & $20(12.9)$ & 0.32 \\
\hline Medical management & $0(0)$ & $1(1.9)$ & $0(0)$ & $1(0.7)$ & 0.37 \\
\hline
\end{tabular}

FTF, face-to-face; PM, peer mentoring.

transferred electronically coded data into a secure database that was constantly password protected with no linkage to any personal identifiers in this file. We used statistical alterations to ensure that individuals cannot be identified through any study dataset. To maximize follow-up rates, the program coordinator used email messages and telephone calls to remind the participants to complete the surveys. The program coordinator contacted participants and their respective social workers to determine reasons for withdrawal or loss to follow-up.

\section{Analytical and Statistical Approaches}

The independent variable was allocation to the FTF PM, online $\mathrm{PM}$, or textbook-only groups. Our outcome variables were scores on domains of the KDQOL-36. The outcome variables were continuous and measured at 3 time points (baseline and 12 and 18 months). Covariates included demographic measures (age, sex, race and ethnicity, marital status, attended or completed college, employment status, and rural vs. urban location). We used repeated measures analysis of variance within the context of a linear mixed-effects model to estimate time-related changes in scores. The data source for covariates other than rural/urban location was predominantly participant self-report. We used type 3 fixed effects mean squares to test the statistical significance of each of the demographic variables. To minimize the limitations of self-report data, we ensured that the questions were clear in wording and that we collected data at time of enrollment and at each follow-up visit (Appendix B). None of the variables had $>10 \%$ missing data. Analyses were by intention to treat. The statistical analyses based on restricted maximum likelihood estimation for the linear mixedeffects model allowed for valid and unbiased conclusions in the presence of data that are missing at random. We used SAS, version 9.4 (SAS Institute Inc., Cary, NC, USA) for data analysis.

\section{Results}

\section{Patient Populations and Demographics}

The CONSORT diagram (Fig. 1) describes the flow of patient participants through the study interventions. We assessed 236 patients with stage 4 or 5 CKD for eligibility. We excluded 81 patients. Of these, 73 did not meet inclusion criteria (no internet access, 61; previous mentoring for $\mathrm{CKD}, 12$ ), and 8 eligible patients declined to participate after receiving more information about the study because of their perceived burden of participating in the study. Using permuted block randomization with 1:1:1 allocation, we randomized 155 patients into 3 groups. All patients began participation in the intervention and completed the baseline assessment. Of these, 117 patients completed the interventions and the 18-month assessment. Among the FTF group, 45 patients completed the allocated intervention and the 12-month assessment and 40 patients completed the 18 -month assessment. Among the online PM group, 45 patients completed the allocated intervention and the 12-month assessment and 42 patients completed the 18-month assessment. Among the textbook-only group, 40 patients completed the allocated intervention and 12-month assessment and 35 patients completed the 18-month assessment. We included 155 patients in the final analyses. 
Table 2. Mean unadjusted domain scores of the Kidney Disease Quality of Life instrument through the study period by the intervention group (intention-to-treat analysis)

\begin{tabular}{|c|c|c|c|}
\hline $\begin{array}{l}\text { Domains and } \\
\text { assessment points }\end{array}$ & $\begin{array}{l}\text { FTF PM } \\
(\text { mean } \pm S D)\end{array}$ & $\begin{array}{l}\text { Online PM } \\
(\text { mean } \pm S D)\end{array}$ & $\begin{array}{l}\text { Textbook only } \\
(\text { mean } \pm \text { SD) }\end{array}$ \\
\hline \multicolumn{4}{|c|}{ Effects of Kidney Disease Score } \\
\hline Baseline & $66.4 \pm 26.6$ & $67.8 \pm 23.7$ & $67.1 \pm 20.0$ \\
\hline 12 months & $75.6 \pm 19.5$ & $75.5 \pm 22.2$ & $62.5 \pm 18.3$ \\
\hline 18 months & $72.9 \pm 22.8$ & $77.6 \pm 22.1$ & $66.0 \pm 18.7$ \\
\hline \multicolumn{4}{|c|}{ Burden of Kidney Disease Score } \\
\hline Baseline & $45.5 \pm 28$ & $45.9 \pm 27.9$ & $48.7 \pm 29.4$ \\
\hline 12 months & $46.7 \pm 28.3$ & $57.6 \pm 28.1$ & $38.9 \pm 27.1$ \\
\hline 18 months & $53 \pm 28.6$ & $59.3 \pm 32.4$ & $45.6 \pm 33.5$ \\
\hline \multicolumn{4}{|c|}{ Symptoms and Problems of Kidney Disease } \\
\hline Baseline & $71.8 \pm 18.9$ & $75.2 \pm 19.9$ & $81.5 \pm 12.3$ \\
\hline 12 months & $80.1 \pm 12.3$ & $84.2 \pm 13.3$ & $77.4 \pm 15.5$ \\
\hline 18 months & $75.2 \pm 17.6$ & $83.2 \pm 14.1$ & $78.0 \pm 14.2$ \\
\hline \multicolumn{4}{|c|}{ SF-12 Physical Composite Summary } \\
\hline Baseline & $37.6 \pm 9.7$ & $37.1 \pm 9.2$ & $39.7 \pm 11.2$ \\
\hline 12 months & $39.5 \pm 8.7$ & $44.9 \pm 8.7$ & $35.3 \pm 9.8$ \\
\hline 18 months & $38.7 \pm 8.7$ & $42.9 \pm 10.3$ & $37.8 \pm 11.2$ \\
\hline \multicolumn{4}{|c|}{ SF-12 Mental Composite Summary } \\
\hline Baseline & $43.6 \pm 11.0$ & $44.3 \pm 10.3$ & $41.6 \pm 8.0$ \\
\hline 12 months & $49.8 \pm 10.0$ & $50.8 \pm 9.5$ & $40.3 \pm 10.6$ \\
\hline 18 months & $47.8 \pm 10.1$ & $52.0 \pm 8.9$ & $45.3 \pm 10$ \\
\hline
\end{tabular}

FTF, face-to-face; PM, peer mentoring; SD, standard deviation; SF, Short-Form.

Assessments consisted of completion of the KDQOL-36 instrument. Table 1 presents the baseline characteristics of the patients. Baseline demographic characteristics did not differ statistically significantly among the 3 groups. Appendix $\mathrm{C}$ documents the details of patients' demographic characteristics.

Kidney Disease Quality of Life-36 Scores

In Table 2, we document the unadjusted mean scores of the EKD, BKD, SPKD, PCS, and MCS of the KDQOL-36 in the 3 groups at baseline, at 12 months, and at 18 months. Table 3 shows the changes in mean scores from the domains of the KDQOL-36 over the study period. At 18 months, online PM led to a statistically significant increase in mean scores of all 5 domains.

Table 4 shows slope estimates, representing changes in the scores from the KDQOL-36 over 18 months, adjusted for demographic variables (race, ethnicity, sex, age quartile, marital status, attended or completed college, employment status, and rural/urban location), using intention-to-treat analysis. Online PM led to a statistically significant increase in slope scores of all 5 do- mains of the KDQOL-36. Compared with textbook only, online PM led to a statistically significant increase in comparisons of slope scores of the BKD $(p=0.04)$, SPKD $(p=0.003)$, and the PCS $(p=0.01)$ domains. Compared with textbook only, FTF PM led to a statistically significant increase in the SPKD domain slope score $(p=0.04)$.

\section{Discussion/Conclusion}

The findings from this clinical trial support the hypothesis that PM improved QOL scores among patients with advanced CKD. Compared with textbook only and FTF PM, among those with internet access, online PM was associated with improvements in scores in all domains of the KDQOL-36. Compared with textbook only, FTF PM was associated with improved SPKD. Our findings are consistent with studies that have shown effectiveness of online social support networks in improving patient-related outcomes. Use of professionally moderated internet discussion groups and peer-led online interventions has been proposed as a strategy for patient engagement, self-management, information exchange, and support for patients with chronic disease. Online peer support groups have enhanced the care of diabetes $[50,51]$. For example, Zrebiec [52] evaluated a web-based educational and emotional resource for patients with diabetes and their family members at the Joslin Diabetes Center. Over 74 months, $74 \%$ of all respondents rated participation in the discussion board as having a positive effect on coping with diabetes, and $71 \%$ rated participation as helping them to feel more hopeful. Lorig et al. [53] found that an internet-based, peer-led chronic disease self-management program (CDSMP) improved health-related behavior change, self-efficacy, and satisfaction with the health care system and reduced health care utilization. Other forms of internet-based interventions associated with improved chronic disease management include discussion boards, computer-tailored feedback, and behavioral ecounseling $[54,55]$. Despite the above-noted findings, uncertainty persists about the effectiveness of such interventions on long-term outcomes of clinical significance. Eysenbach and colleagues [56] cited lack of sufficient evidence to support use of peers for online programs. They suggested that research is required to evaluate specific conditions for which the effect of online PM might be maximized. A Cochrane review concluded that peer-led self-management programs may lead to small, short-term improvement; it reported no evidence to suggest that 
Table 3. Unadjusted changes in mean scores of domains of the Kidney Disease Quality of Life instrument through the study period by the intervention group (intention-to-treat analysis)

\begin{tabular}{|c|c|c|c|c|c|c|}
\hline Domains and assessment points & $\begin{array}{l}\text { FTF PM group } \\
\text { change in mean } \\
\text { score } \pm \text { SE; } 95 \% \text { CI }\end{array}$ & $p$ value & $\begin{array}{l}\text { Online PM group } \\
\text { change in mean } \\
\text { score } \pm \text { SE; } 95 \% \text { CI }\end{array}$ & $p$ value & $\begin{array}{l}\text { Textbook-only group } \\
\text { change in mean } \\
\text { score } \pm \text { SE; } 95 \% \text { CI }\end{array}$ & $\begin{array}{l}p \\
\text { value }\end{array}$ \\
\hline \multicolumn{7}{|l|}{ Effects of Kidney Disease Score } \\
\hline 12 months compared with baseline & $9.2 \pm 4.8 ;-0.3,18.7$ & 0.06 & $7.7 \pm 4.7 ;-1.6,17.0$ & 0.10 & $-4.6 \pm 4.1 ;-12.7,3.5$ & 0.26 \\
\hline 18 months compared with 12 months & $-2.7 \pm 4.6 ;-11.8,6.4$ & 0.56 & $2.1 \pm 4.8 ;-7.5,11.7$ & 0.66 & $3.5 \pm 4.3 ;-5.0,12.0$ & 0.42 \\
\hline 18 months compared with baseline & $6.5 \pm 5.3 ;-4.0,17.0$ & 0.22 & $9.8 \pm 4.8 ; 0.2,19.4$ & 0.04 & $-1.1 \pm 4.27 ;-9.6,7.4$ & 0.80 \\
\hline \multicolumn{7}{|l|}{ Burden of Kidney Disease Score } \\
\hline 18 months compared with 12 months & $6.3 \pm 5.8 ;-5.2,17.8$ & 0.28 & $1.7 \pm 6.6 ;-11.5,14.9$ & 0.80 & $6.7 \pm 7.3 ;-7.8,21.2$ & 0.36 \\
\hline 18 months compared with baseline & $7.5 \pm 5.9 ;-4.3,19.3$ & 0.21 & $13.4 \pm 6.2 ; 1.0,25.8$ & 0.03 & $-3.1 \pm 6.8 ;-16.7,10.5$ & 0.65 \\
\hline \multicolumn{7}{|l|}{ Symptoms and Problems of Kidney Disease } \\
\hline 12 months compared with baseline & $8.3 \pm 3.4 ; 1.5,15.1$ & 0.01 & $9.0 \pm 3.6 ; 1.9,16.1$ & 0.01 & $-4.1 \pm 3 ;-10.1,1.9$ & 0.18 \\
\hline 18 months compared with 12 months & $-4.9 \pm 3.4 ;-11.7,1.9$ & 0.15 & $-1.0 \pm 3.0 ;-7.0,4.9$ & 0.74 & $0.6 \pm 3.6 ;-6.5,7.7$ & 0.87 \\
\hline 18 months compared with baseline & $3.4 \pm 3.9 ;-4.3,11.0$ & 0.38 & $8.0 \pm 3.6 ; 0.8,15.2$ & 0.03 & $-3.5 \pm 2.9 ;-9.2,2.2$ & 0.23 \\
\hline \multicolumn{7}{|l|}{ SF-12 Mental Composite Summary } \\
\hline 12 months compared with baseline & $6.2 \pm 2.2 ; 1.8,10.6$ & 0.006 & $6.5 \pm 2.1 ; 2.4,10.6$ & 0.002 & $-1.3 \pm 2.0 ;-5.3,2.7$ & 0.52 \\
\hline 18 months compared with 12 months & $-2 \pm 2.2 ;-6.5,2.5$ & 0.37 & $1.2 \pm 2.0 ;-2.8,5.2$ & 0.55 & $5 \pm 2.5 ;-0.09,9.9$ & 0.05 \\
\hline 18 months compared with baseline & $4.2 \pm 2.2 ;-0.2,8.6$ & 0.06 & $7.7 \pm 2.0 ; 3.7,11.7$ & $<0.001$ & $3.7 \pm 1.9 ;-0.2,7.6$ & 0.06 \\
\hline
\end{tabular}

Higher score indicates better outcome; negative change in score indicates worse outcome over time. FTF, face-to-face; PM, peer mentoring; SE, standard error; CI, confidence interval; SF-12, Short-Form-12.

these programs lead to significant long-term improvements in health-related outcomes [57].

General conclusions about effectiveness of PM based on review of clinical trials are limited for several reasons. These include the substantial variation in online PM programs, the ambiguity about differentiation between PM programs and support groups, the variety of disease states, the severity of illness, and the variety of studied outcomes. Our study was unique in several aspects and addressed some of the concerns about the effect of PM. Some of the key features of a successful PM program include sufficient training and ongoing support for peer mentors and regular opportunities for mentors to receive additional training. In our study, the mentors were selected based on their compliance with their own treatment, willingness to learn, ability to communicate effectively, empathy, and respectfulness towards other individuals' differences. The peer mentors received formal and standardized training. We monitored the mentoring program for consistent delivery. The mentor candidates provided, and received, regular feedback and evaluation. At the beginning of each session, the program coordinator reviewed the evaluations from the previous session with the candidates, and feasible suggestions were incorporated into the training. A key component of success and sustainability of PM is satisfaction of the mentors with the program. In focus group studies leading up to the designing of the trial, and during the continuing education sessions, the mentors shared their actual experiences. They reported satisfaction with their roles and perceived the bonding experience a very positive influence. Another unique feature of our study was the fact that the disease state and severity of illness were well defined. Finally, the outcomes were distinct and measurable over a period of 18 months. Possible reasons for the superiority of online PM compared with FTF PM include convenient access without the restrictions of arranging for a meeting and flexibility of time of communication with less concern about imposing on the mentor's time. There was a higher rate of attendance/completion of college in the online PM group compared with the FTF PM group; although the difference was not statistically significant, higher education attainment might have contributed to the improved outcomes among the online PM group. Furthermore, online communication allows for questions and answers to be presented in a less-pressured setting, permitting time 
Table 4. Changes in scores on the Kidney Disease Quality of Life instrument through the study period among the groups (intention-to-treat analysis)

\begin{tabular}{|c|c|c|c|}
\hline Individual measures and comparisons ${ }^{\mathrm{a}}$ & $\begin{array}{l}\text { Slope estimate }{ }^{\mathrm{b}} \\
\text { ( } \pm \text { standard error) }\end{array}$ & $\begin{array}{l}95 \% \\
\text { confidence interval }\end{array}$ & $p$ value \\
\hline \multicolumn{4}{|l|}{ Effects of Kidney Disease (EKD) } \\
\hline FTF PM slope & $2.21 \pm 1.68$ & $-1.10,5.52$ & 0.19 \\
\hline Online PM slope & $4.13 \pm 1.65$ & $0.87,7.40$ & 0.01 \\
\hline Textbook-only slope & $-0.50 \pm 1.76$ & $-3.97,2.97$ & 0.77 \\
\hline FTF PM slope versus online PM slope & $-1.93 \pm 2.35$ & $-6.58,2.72$ & 0.41 \\
\hline FTF PM slope versus textbook only & $2.71 \pm 2.42$ & $-2.08,7.50$ & 0.26 \\
\hline Online PM slope versus textbook-only slope & $4.64 \pm 2.41$ & $-0.12,9.40$ & 0.06 \\
\hline \multicolumn{4}{|l|}{ Burden of Kidney Disease (BKD) } \\
\hline FTF PM slope & $3.00 \pm 2.16$ & $-1.27,7.27$ & 0.17 \\
\hline Online PM slope & $5.44 \pm 2.12$ & $1.24,9.63$ & 0.01 \\
\hline Textbook-only slope & $-0.99 \pm 2.28$ & $-5.50,3.53$ & 0.67 \\
\hline FTF PM slope versus online PM slope & $-2.44 \pm 3.03$ & $-8.42,3.54$ & 0.42 \\
\hline FTF PM slope versus textbook-only slope & $3.99 \pm 3.14$ & $-2.22,10.19$ & 0.21 \\
\hline Online PM slope versus textbook-only slope & $6.43 \pm 3.12$ & $0.27,12.58$ & 0.04 \\
\hline \multicolumn{4}{|l|}{ Symptoms and Problems of Kidney Disease (SPKD) } \\
\hline FTF PM slope & $3.41 \pm 2.27$ & $-0.46,6.36$ & 0.13 \\
\hline Online PM slope & $6.00 \pm 2.20$ & $3.09,8.91$ & 0.006 \\
\hline Textbook-only slope & $-2.71 \pm 1.94$ & $-6.20,0.78$ & 0.16 \\
\hline FTF PM slope versus online PM slope & $-2.59 \pm 3.17$ & $-6.08,0.90$ & 0.42 \\
\hline FTF PM slope versus textbook-only slope & $6.12 \pm 2.98$ & $2.62,9.38$ & 0.04 \\
\hline Online PM slope versus textbook-only slope & $8.71 \pm 2.94$ & $5.35,12.07$ & 0.003 \\
\hline \multicolumn{4}{|l|}{ SF-12 Physical Composite Summary Score } \\
\hline FTF PM slope & $0.64 \pm 0.80$ & $-0.94,2.22$ & 0.43 \\
\hline Online PM slope & $2.50 \pm 0.79$ & $0.95,4.06$ & 0.001 \\
\hline Textbook-only slope & $-0.70 \pm 0.84$ & $-2.36,0.97$ & 0.41 \\
\hline FTF PM slope versus online PM slope & $-1.86 \pm 1.12$ & $-4.08,0.36$ & 0.10 \\
\hline FTF PM slope versus textbook-only slope & $1.34 \pm 1.16$ & $-0.96,3.63$ & 0.25 \\
\hline Online PM slope versus textbook-only slope & $3.20 \pm 1.15$ & $0.92,5.48$ & 0.01 \\
\hline \multicolumn{4}{|l|}{ SF-12 Mental Composite Summary Score } \\
\hline FTF PM slope & $1.43 \pm 0.86$ & $-0.28,3.13$ & 0.10 \\
\hline Online PM slope & $3.46 \pm 0.85$ & $1.78,5.13$ & $<0.001$ \\
\hline Textbook slope & $1.13 \pm 0.91$ & $-0.66,2.92$ & 0.21 \\
\hline FTF PM slope versus online PM slope & $-2.03 \pm 1.21$ & $-4.42,0.36$ & 0.10 \\
\hline FTF PM slope versus textbook-only slope & $0.30 \pm 1.25$ & $-2.17,2.77$ & 0.81 \\
\hline Online PM slope versus textbook-only slope & $2.32 \pm 1.24$ & $-0.13,4.78$ & 0.06 \\
\hline
\end{tabular}

FTF, face-to-face; PM, peer mentoring; SF-12, Short-Form-12. a Adjusted for race, ethnicity, sex, age quartile, marital status, attended or completed college, employment status, and rural/urban location. ${ }^{\mathrm{b}}$ The slope estimates represent change in scores in standard points over 18 months.

to think, and promotes mutually more thoughtful communication.

The major strength of the study was the engagement of patients, caregivers, and other stakeholders in various stages of the study. Stakeholders were involved in designing the study, recruiting participants, delivering the interventions, and dissemination of the interim results to the community. Another strength was the relatively strong adherence to protocol and completion of the interven- tion, although patients with stage 4 or 5 CKD have substantial numbers and high severity of comorbidities that might prevent them from participating in clinical trials lasting more than a few months. Although the overall loss to follow-up was higher than expected, to minimize potential bias resulting from the effect of loss to follow-up, we used intention-to-treat analysis. The highest loss to follow-up occurred in the textbook-only (control) group, reducing concern about burden of intervention as the 
main reason for drop out. Loss to follow-up rates were similar between the 2 active intervention groups. Our study also had several limitations. First, we limited the participants to English-speaking subjects with computer literacy and those with internet access. Second, adherence to review of material by the textbook-only group was by self-report without monitoring by the study team. Third, although the program coordinator monitored adherence to the PFPP protocol, we did not collect information as part of the research, and we did not include frequency of contact in the analyses. Fourth, although the total number of participants included in the final analyses was sufficient per our power calculations, the number of participants belonging to certain subpopulations, such as rural and Hispanic patients, was limited, not allowing for exploratory subgroup analyses in those populations. Fifth, we conducted the trial in central Pennsylvania, limiting geographic generalizability. Sixth, because of the nature of the disease and its treatment, patients with $\mathrm{CKD}$, particularly those on hemodialysis, already belong to a community and are likely more willing than patients with other chronic diseases to actively engage in peer-related activities. Seventh, the vast majority of patients $(142 / 155=$ 91.6\%) were patients with CKD5 on dialysis, limiting applicability of the study to patients with CKD of all stages. Finally, the small number of patients on modalities of treatment other than hemodialysis did not allow for accounting for the effect of modality on outcome measures.

As suggested by our findings, larger studies drawing participants from diverse backgrounds and geographic locales, as well as a larger number of CKD patients not on hemodialysis, and patients with earlier stages of CKD will allow for more robust subgroup analyses. We concur with the recommendations from the Cochrane review [57] of peer-led programs that future research should be focused on assessing longer-term outcomes of interest to patients, such as repeated hospitalizations and satisfaction with treatment decisions. Other potential areas of research include assessing outcomes such as fatigue and cognition, examining relationships between health literacy and outcomes, and evaluating the role and end results of PM among children and adolescents, among patients with earlier stages of CKD, and among patients with other chronic disease states. Because we used the existing infrastructure of our partnering organization, the Kidney Foundation of Central Pennsylvania, to deliver the interventions, our costs were limited to developing and maintaining the online platform and covering research staff salaries and participant stipends. Therefore, detailed costeffectiveness studies of interventions that include PM are needed to help clarify the feasibility of such interventions in settings where a new infrastructure might be required. Finally, although we do not believe that the interventions in this trial were complex, using process evaluation to test these interventions is a potential area for future research [58]. We conclude that online PM is an effective strategy that leads to improved QOL among patients with CKD.

\section{Acknowledgements}

The investigators wish to acknowledge the following for their assistance in various stages of the study:

- All patients and caregivers who participated in the study as peer mentors, as members of the advisory groups, or as study subjects; without their active and enthusiastic participation, this study would not have been possible.

- The Kidney Foundation of Central Pennsylvania (KFCP) and members of its Board of Directors who served as members of the Community Advisory Board.

- Parts of this study was presented in an abstract form at the Annual Meeting of the American Society of Nephrology November 7-10, 2019, in Washington, D.C.

\section{Statement of Ethics}

The research was conducted according to principles having their origin in the Declaration of Helsinki. Written informed consent was obtained from all participants. The protocol was reviewed and approved by the Pennsylvania State University College of Medicine Institutional Review Board. The clinical trial was registered with Clinicaltrials.gov (NCT02429115).

\section{Conflict of Interest Statement}

The authors declare that they have no relevant financial interests. Nasrollah Ghahramani is a member of the Board of Directors of the Kidney Foundation of Central Pennsylvania.

\section{Funding Sources}

Research reported in this article was funded through a PatientCentered Outcomes Research Institute (PCORI) Award CDR1310-07055 (to Nasrollah Ghahramani). The statements in this article are solely the responsibility of the authors and do not necessarily represent the views of the Patient-Centered Outcomes Research Institute (PCORI), its Board of Governors, or Methodology Committee. V.C., J.K., E.L., and C.S. were coinvestigators on the study. The funding agency (Patient-Centered Outcomes Research Institute) and the employer (Penn State College of Medicine/Penn State Health) did not have a role in the study design; collection, analysis, and interpretation of data; writing the report; and the decision to submit the report for publication. 


\section{Author Contributions}

Research idea and study design: N.G., V.C., J.K., E.L., and C.S.; data acquisition: N.G.; data analysis/interpretation: N.G., V.C., J.K., E.L., and C.S.; statistical analysis: V.C. Each author contributed important intellectual content during manuscript drafting or revision, accepts personal accountability for the author's own contributions, and agrees to ensure that questions pertaining to the accuracy or integrity of any portion of the work are appropriately investigated and resolved.

\section{Availability of Data and Material}

Deidentified participant data will be made available to qualified external researchers, for a specific purpose in accordance with the PCORI Policy for Data Management and Data Sharing Plan: https://www.pcori.org/about-us/governance/policy-data-management-and-data-sharing.

\section{References}

1 Saran R, Robinson B, Abbott KC, Agodoa LYC, Bragg-Gresham J, Balkrishnan R, et al. US renal data system 2018 annual data report: epidemiology of kidney disease in the United States. Am J Kidney Dis. 2019;73(3 Suppl 1): A7-8.

2 Kalender B, Ozdemir AC, Dervisoglu E, Ozdemir O. Quality of life in chronic kidney disease: effects of treatment modality, depression, malnutrition and inflammation. Int $\mathrm{J}$ Clin Pract. 2007;61(4):569-76.

3 Walters BA, Hays RD, Spritzer KL, Fridman M, Carter WB. Health-related quality of life, depressive symptoms, anemia, and malnutrition at hemodialysis initiation. Am J Kidney Dis. 2002;40(6):1185-94.

4 Tsai YC, Hung CC, Hwang SJ, Wang SL, Hsiao SM, Lin MY, et al. Quality of life predicts risks of end-stage renal disease and mortality in patients with chronic kidney disease. Nephrol Dial Transplant. 2010;25(5): 1621-6.

5 DeCuir JR. Praying for the power of patience (POP): life is great, even with kidney failure!. Adv Ren Replace Ther. 1998;5(3):252-3.

6 Hedman H. Patient compliance in renal replacement therapy: whose problem is it? The patient's perspective. Edtna Erca J. 1998; 24(4):15-6.

7 Waterman $\mathrm{AD}$, Morgievich M, Cohen DJ, Butt Z, Chakkera HA, Lindower C, et al. Living donor kidney transplantation: improving education outside of transplant centers about live donor transplantation: recommendations from a consensus conference. Clin J Am Soc Nephrol. 2015;10(9):1659-69.

8 LaPointe Rudow D, Hays R, Baliga P, Cohen DJ, Cooper M, Danovitch GM, et al. Consensus conference on best practices in live kidney donation: recommendations to optimize education, access, and care. Am J Transplant. 2015;15(4):914-22.

9 Lopez-Vargas PA, Tong A, Howell M, Craig JC. Educational interventions for patients with CKD: a systematic review. Am J Kidney Dis. 2016;68(3):353-70.

10 Hsu CK, Lee CC, Chen YT, Ting MK, Sun CY, Chen CY, et al. Multidisciplinary predialysis education reduces incidence of peritonitis and subsequent death in peritoneal dialysis patients: 5-year cohort study. PLoS One. 2018;13(8):e0202781-e.
11 Covic A, Bammens B, Lobbedez T, Segall L, Heimbürger $\mathrm{O}$, van Biesen $\mathrm{W}$, et al. Educating end-stage renal disease patients on dialysis modality selection: clinical advice from the European Renal Best Practice (ERBP) Advisory Board. Nephrol Dial Transplant. 2010; 25(6):1757-9.

12 Finkelstein FO, Story K, Firanek C, Barre P, Takano T, Soroka S, et al. Perceived knowledge among patients cared for by nephrologists about chronic kidney disease and endstage renal disease therapies. Kidney Int. 2008;74(9):1178-84

13 Whaley-Connell A, Shlipak MG, Inker LA, Kurella Tamura M, Bomback AS, Saab G, et al. Awareness of kidney disease and relationship to end-stage renal disease and mortality. Am J Med. 2012;125(7):661-9.

14 Iles-Smith H. Perceptions and experiences of pre-dialysis patients. EDTNA ERCA J. 2005; 31(3):130-3.

15 Burns T, Fernandez R, Stephens M. The experiences of adults who are on dialysis and waiting for a renal transplant from a deceased donor: a systematic review. JBI Database System Rev Implement Rep. 2015;13(2):169211.

16 Juhnke J, Curtin RB. New study identifies ESRD patient education needs. Nephrol News Issues. 2000;14(6):38-9.

17 Klang B, Björvell H, Clyne N. Predialysis education helps patients choose dialysis modality and increases disease-specific knowledge. J Adv Nurs. 1999;29(4):869-76.

18 Bath J, Tonks S, Edwards P. Psychological care of the haemodialysis patient. EDTNA ERCA J. 2003;29(2):85-8.

19 Tweed AE, Ceaser K. Renal replacement therapy choices for pre-dialysis renal patients. $\mathrm{Br}$ J Nurs. 2005;14(12):659-64.

20 Heisler M. Different models to mobilize peer support to improve diabetes self-management and clinical outcomes: evidence, logistics, evaluation considerations and needs for future research. Fam Pract. 2010;27(Suppl 1): I23-32.

21 Dennis C-L. Peer support within a health care context: a concept analysis. Int J Nurs Stud. 2003;40(3):321-32.

22 Lucksted A, McNulty K, Brayboy L, Forbes C. Initial evaluation of the peer-to-peer program. Psychiatr Serv. 2009;60(2):250-3.
23 Wright L, Pennington JJ, Abbey S, Young E, Haines J, Ross H. Evaluation of a mentorship program for heart transplant patients. J Heart Lung Transplant. 2001;20(9):1030-3.

24 Mandalia PK, Stone MA, Davies MJ, Khunti K, Carey ME. Diabetes self-management education: acceptability of using trained lay educators. Postgrad Med J. 2014;90(1069):638-42.

25 Jerson B, D'Urso C, Arnon R, Miloh T, Iyer K, Kerkar N, et al. Adolescent transplant recipients as peer mentors: a program to improve self-management and health-related quality of life. Pediatr Transplant. 2013;17(7):61220.

26 Hibbard MR, Cantor J, Charatz H, Rosenthal R, Ashman T, Gundersen N, et al. Peer support in the community: initial findings of a mentoring program for individuals with traumatic brain injury and their families. J Head Trauma Rehabil. 2002;17(2):112-31.

27 Ahola Kohut S, Stinson JN, Ruskin D, Forgeron P, Harris L, van Wyk M, et al. iPeer2Peer program: a pilot feasibility study in adolescents with chronic pain. Pain. 2016;157(5): 1146-55.

28 Doyle M. Peer support and mentorship in a US rare disease community: findings from the cystinosis in emerging adulthood study. $\mathrm{Pa}$ tient. 2015;8(1):65-73.

29 Perry E, Swartz J, Brown S, Smith D, Kelly G, Swartz R. Peer mentoring: a culturally sensitive approach to end-of-life planning for long-term dialysis patients. Am J Kidney Dis. 2005;46(1):111-9.

30 Pierce P, Asick R, Weaver M. Trained ESRD mentors: an important resource for total patient care. Nephrol News Issues. 2009;23(3): 36. 8, 40 passim.

31 Ghahramani N, Asick R, Hodge JM. Patient and family partner program. 2013 [cited 2013 Dec 27]. Available from: http://www.kfcp. org/WhatWeDo/PatientandFamilyPartnerProgram.aspx.

32 Hays RD, Kallich JD, Mapes DL, Coons SJ, Carter WB. Development of the kidney disease quality of life (KDQOL) instrument. Qual Life Res. 1994;3(5):329-38.

33 Peipert JD, Bentler PM, Klicko K, Hays RD. Psychometric properties of the kidney disease quality of life 36-item short-form survey (KDQOL-36) in the United States. Am J Kidney Dis. 2018;71(4):461-8. 
34 Korevaar JC, Merkus MP, Jansen MA, Dekker FW, Boeschoten EW, Krediet RT. Validation of the KDQOL-SF: a dialysis-targeted health measure. Qual Life Res. 2002;11(5):437-47.

35 Fukuhara S, Lopes AA, Bragg-Gresham JL, Kurokawa K, Mapes DL, Akizawa T, et al. Health-related quality of life among dialysis patients on three continents: the Dialysis Outcomes and Practice Patterns Study. Kidney Int. 2003;64(5):1903-10.

36 Mapes DL, Bragg-Gresham JL, Bommer J, Fukuhara S, McKevitt P, Wikström B, et al. Health-related quality of life in the Dialysis Outcomes and Practice Patterns Study (DOPPS). Am J Kidney Dis. 2004;44(5 Suppl 2):54-60.

37 Bakewell AB, Higgins RM, Edmunds ME. Quality of life in peritoneal dialysis patients: decline over time and association with clinical outcomes. Kidney Int. 2002;61(1):239-48.

38 Manns B, Johnson JA, Taub K, Mortis G, Ghali WA, Donaldson C. Quality of life in patients treated with hemodialysis or peritoneal dialysis: what are the important determinants? Clin Nephrol. 2003;60(5):341-51.

39 Lopes AA, Bragg-Gresham JL, Satayathum S, McCullough K, Pifer T, Goodkin DA, et al. Health-related quality of life and associated outcomes among hemodialysis patients of different ethnicities in the United States: the Dialysis Outcomes and Practice Patterns Study (DOPPS). Am J Kidney Dis. 2003; 41(3):605-15

40 Peipert JD, Nair D, Klicko K, Schatell DR, Hays RD. Kidney disease quality of life 36item short form survey (KDQOL-36) normative values for the United States dialysis population and new single summary score. J Am Soc Nephrol. 2019;30(4):654-63.

41 Mapes DL, Lopes AA, Satayathum S, McCullough KP, Goodkin DA, Locatelli F, et al. Health-related quality of life as a predictor of mortality and hospitalization: the Dialysis Outcomes and Practice Patterns Study (DOPPS). Kidney Int. 2003;64(1):339-49.
42 Lorig KR, Ritter PL, Laurent DD, Plant K. Internet-based chronic disease self-management: a randomized trial. Med Care. 2006; 44(11):964-71.

43 Knox L, Huff J, Graham D, Henry M, Bracho A, Henderson C, et al. What peer mentoring adds to already good patient care: implementing the Carpeta Roja peer mentoring program in a well-resourced health care system. Ann Fam Med. 2015;13(Suppl 1):S59-65.

44 Sandhu S, Veinot P, Embuldeniya G, Brooks $S$, Sale J, Huang S, et al. Peer-to-peer mentoring for individuals with early inflammatory arthritis: feasibility pilot. BMJ Open. 2013; 3(3):e002267.

45 Maslow GR, Chung RJ. Systematic review of positive youth development programs for adolescents with chronic illness. Pediatrics. 2013;131(5):e1605.

46 Embuldeniya G, Veinot P, Bell E, Bell M, Nyhof-Young J, Sale JE, et al. The experience and impact of chronic disease peer support interventions: a qualitative synthesis. Patient Educ Couns. 2013;92(1):3-12.

47 Enriquez M, Conn VS. Peers as facilitators of medication adherence interventions: a review. J Prim Care Community Health. 2016; 7(1):44-55.

48 Joshi A, Arutagi V, Nahar N, Tiwari S, Singh D, Sethia S. Diabetes ongoing sustainable care and treatment (DOST): a strategy for informational deliverance through visual dynamic modules sustained by near peer mentoring. J Family Med Prim Care. 2016;5(2):270-5.

49 Wenzel L, Huang HQ, Monk BJ, Rose PG, Cella D. Quality-of-life comparisons in a randomized trial of interval secondary cytoreduction in advanced ovarian carcinoma: a Gynecologic Oncology Group study. J Clin Oncol. 2005;23(24):5605-12.
50 McKay HG, King D, Eakin EG, Seeley JR, Glasgow RE. The diabetes network internetbased physical activity intervention: a randomized pilot study. Diabetes Care. 2001; 24(8):1328-34.

51 Tate DF, Jackvony EH, Wing RR. Effects of Internet behavioral counseling on weight loss in adults at risk for type 2 diabetes: a randomized trial. JAMA. 2003;289(14):1833-6.

52 Zrebiec JF. Internet communities: do they improve coping with diabetes? Diabetes Educ. 2005;31(6):825-36

53 Lorig KR, Ritter PL, Dost A, Plant K, Laurent DD, McNeil I. The expert patients programme online, a 1-year study of an internetbased self-management programme for people with long-term conditions. Chronic Illn. 2008;4(4):247-56.

54 Tate DF, Jackvony EH, Wing RR. A randomized trial comparing human e-mail counseling, computer-automated tailored counseling, and no counseling in an internet weight loss program. Arch Intern Med. 2006;166(15): $1620-5$.

55 Tate DF, Jackvony EH, Wing RR. Effects of internet behavioral counseling on weight loss in adults at risk for type 2 diabetes: a randomized trial. JAMA. 2003;289(14):1833-6.

56 Eysenbach G, Powell J, Englesakis M, Rizo C, Stern A. Health related virtual communities and electronic support groups: systematic review of the effects of online peer to peer interactions. BMJ. 2004;328(7449):1166.

57 Foster G, Taylor SJ, Eldridge SE, Ramsay J, Griffiths CJ. Self-management education programmes by lay leaders for people with chronic conditions. Cochrane Database Syst Rev. 2007(4):CD005108.

58 Moore GF, Audrey S, Barker M, Bond L, Bonell C, Hardeman W, et al. Process evaluation of complex interventions: Medical Research Council guidance. BMJ. 2015;350: h1258. 